I BIENAL LATINOAMERICANA DIDH

\title{
Impacto y desafíos de la Comisión Interamericana de Derechos Humanos en el actual contexto regional
}

\author{
Impact and challenges of the Inter-American Commission \\ on Human Rights in the current regional context
}

\author{
Antonia Urrejola Noguera \\ Comisión Interamericana de Derechos Humanos, Estados Unidos
}

\begin{abstract}
RESUMEN Este artículo hace un análisis histórico de la labor de la Comisión Interamericana de Derechos Humanos (CIDH) durante sus 60 años de historia, resaltando los principales impactos que, a juicio de la autora, ha tenido el organismo a través de sus diversos mecanismos. Asimismo, hace un análisis de la situación actual de derechos humanos en el continente americano para, a partir de dicho contexto, establecer los principales desafíos que, a su juicio, debe enfrentar la CIDH. Finalmente, el artículo hace referencia a la contingencia de la pandemia del covid-19, que estaba en pleno desarrollo a la fecha de cierre del artículo, indicando las recomendaciones que hasta ese momento ha tomado la CIDH para resguardar que las medidas adoptadas por los Estados al enfrentar la pandemia sean respetuosas de los derechos humanos y estándares interamericanos.
\end{abstract}

PALABRAS CLAVE CIDH, desafíos del Sistema Interamericano, impactos, 60 años, covid-19, derechos humanos.

ABSTRACT This article makes a historical analysis of the work of the Inter-American Commission on Human Rights (IACHR) during its 6o-year history, highlighting the main impacts that, in the author's opinion, the organization has had through its various mechanisms. Likewise, it analyzes the current human rights situation in the American continent and based on that context, establishes the main challenges that, in her opinion, the IACHR must face. Finally, the article refers to the consequences on human rights of the Covid-19 pandemic, which was affecting the world at the closing date of the article, indicating the recommendations that the IACHR has adopted to that moment so that the measures implemented by the States when facing the pandemic, are respectful of human rights and inter-American standards. 
KEYWORDS Challenges of the inter-American system, impacts, 6o years, Covid-19, human rights.

\section{Antecedentes sobre la creación de la CIDH y sus impactos}

$\mathrm{Al}$ ser creada la Comisión Interamericana de Derecho Humanos (CIDH) en 1959, ${ }^{1}$ se le encomendó la preparación de estudios e informes sobre la situación de los derechos humanos en la región, la formulación de recomendaciones y la asesoría en materia de derechos humanos en calidad de órgano ejecutivo de la Organización de los Estados Americanos (OEA). En un principio, entonces, se consideró que la $\mathrm{CIDH}$ simplemente se encargaría de hacer esos estudios de forma general y esporádica, y que sus recomendaciones no tendrían mayor peso en la medida en que serían formuladas de manera general, con el objetivo de examinar la relación intrínseca entre derechos humanos y democracia establecida por la OEA.

Sin embargo, desde sus inicios la Comisión emitió solicitudes de información a los Estados, y esta información empezó a formar parte del trámite de casos individuales, así como de los informes de la CIDH sobre la situación de los derechos humanos en ciertos países. De la misma forma, la Comisión insistió en sesionar fuera de la sede, sesiones que luego se convirtieron en investigaciones in loco, lo que permitió a la Comisión cumplir su mandato y responder a la grave situación de derechos humanos en el hemisferio.

Es importante destacar que por dos décadas, y hasta la entrada en vigor de la Corte Interamericana de Derechos Humanos (Corte IDH) en 1979, la Comisión operó como el único órgano de protección del sistema interamericano. Es importante destacar además que la CIDH fue el primer órgano internacional en tramitar peticiones individuales sin que esta facultad hubiera estado precedida por un tratado de derechos humanos que le otorgara tal competencia. Las herramientas de trabajo desarrolladas por la CIDH fueron entonces reconocidas primero por su Reglamento del 2 de mayo de 1967, pero recién tuvo un mandato expreso cuando en 1969 se aprobó la Convención Americana de Derechos Humanos (CADH).

\section{Monitoreo}

La utilización de las visitas in loco fue y ha sido una de sus principales herramientas para combatir las violaciones masivas y sistemáticas de derechos humanos, como

1. Los ministros de Relaciones Exteriores de 21 países del hemisferio firmaron la Declaración de Santiago, además de acordar avanzar en la adopción de una Convención Americana sobre Derechos Humanos y crear dos órganos que tendrían como principal responsabilidad velar por la tutela y observancia de estos derechos. 
una de las consecuencias de la adopción de la Convención Americana. Por medio de ellas, la CIDH fue marcando su presencia en el terreno y definiendo uno de sus roles, a mi juicio, fundamentales: una voz de alerta temprana frente a la comunidad internacional.

Algunos ejemplos emblemáticos de visitas in loco de la CIDH durante su historia son:

La visita a Nicaragua que hizo la Comisión en 1978, por mandato de la Asamblea General de la OEA. El informe de la Comisión fue devastador para la dictadura de Somoza, quien perdió todo apoyo internacional al punto de ser destituido dos o tres días después de que la Comisión presentara su informe a la OEA. ${ }^{2}$

La visita de la Comisión a Argentina ${ }^{3}$ en 1979 tuvo un enorme impacto en la sociedad y en el hemisferio, y logró documentar un patrón sistemático de desapariciones forzadas, que fue uno de los factores que contribuyó a la caída de la dictadura. Durante su trabajo en terreno, la Comisión pudo visitar centros de detención clandestinos y reunirse con decenas de detenidos. Esta labor permitió reportar a la comunidad internacional sobre las violaciones sistemáticas a los derechos humanos que ocurrían en Argentina, en especial sobre las desapariciones forzadas. Cabe notar que, hasta la visita de la Comisión, otros órganos internacionales no habían prestado mayor atención a la situación de derechos humanos en el país, y la intervención de la Comisión fue clave para salvar muchas vidas de personas que estaban detenidas en forma clandestina y destinadas a ser desaparecidas forzosamente.

De la misma manera, décadas después, el informe de la visita de la Comisión al Perú 4 denunció de manera enfática las violaciones a los derechos humanos durante el Gobierno del presidente Fujimori y jugó un rol importante en la presión internacional para su dimisión.

Otro caso más reciente es el trabajo que ha seguido la CIDH en Nicaragua, a partir de su visita el 2018 después del inicio de la crisis en abril de ese año. En efecto, tras la visita al país del 17 al 21 de mayo del 2018, la Comisión presentó su informe «Graves violaciones a los derechos humanos en el contexto de las protestas sociales en Nicaragua», ${ }^{5}$ en el cual se reveló que la violencia estatal siguió un patrón común, caracterizado por el uso excesivo y arbitrario de la fuerza policial, el uso de grupos parapoliciales o grupos de choque con la aquiescencia, tolerancia y colaboración de

2. «Informe sobre la situación de los derechos humanos en Nicaragua», Comisión Interamericana de Derechos Humanos, OEA/Ser.L/V/II 45, 17 de noviembre de 1979.

3. «Informe sobre la situación de los derechos humanos en Argentina», Comisión Interamericana de Derechos Humanos, OEA/Ser.L/V/II 49, 11 de abril de 1980.

4. "Comunicado de prensa N20/98: Visita in loco de la CIDH a Perú», Comisión Interamericana de Derechos Humanos, 13 de noviembre de 1998.

5. "Graves violaciones a los derechos humanos en el marco de las protestas sociales en Nicaragua», Comisión Interamericana de Derechos Humanos, 2018, disponible en https://bit.ly/3b9DC1j. 
las autoridades estatales, intimidaciones y amenazas contra líderes de movimientos sociales, un patrón de detenciones arbitrarias de jóvenes y adolescentes que participaban en protestas, irregularidades en el inicio de las investigaciones respecto de los asesinatos y lesiones ocurridos en el este contexto, obstáculos en el acceso a la atención médica de urgencia a los heridos como forma de represalia por su participación en las manifestaciones, la difusión de propaganda y campañas de estigmatización, medidas de censura directa e indirecta. Durante la primera etapa de la represión, se atendieron numerosas víctimas con impactos de bala en la cabeza, los ojos, el cuello y el tórax, así como en la espalda. La mecánica y trayectoria de los disparos indicarían la existencia de un patrón de ejecuciones extrajudiciales y la participación de francotiradores. Sin duda, el informe de la Comisión permitió darle visibilidad a la crisis de derechos humanos que vivía y vive Nicaragua ante la comunidad internacional. Sinceramente, creo que hay un antes y un después en cuanto a la respuesta de la comunidad internacional respecto de lo que estaba sucediendo en el país.

Estos ejemplos dan cuenta, desde mi perspectiva, de uno de los roles fundamentales de la CIDH hasta hoy: el monitoreo de la situación de derechos humanos de la región, a través de las visitas in loco, que permite visibilizar graves situaciones de derechos humanos en los distintos países. Sin duda, estas visitas son solo uno de los diversos mecanismos que tiene la CIDH para denunciar ante la comunidad internacional la situación de derechos humanos en las Américas.

\section{Sistema de peticiones y casos}

En paralelo al desarrollo de este rol como portavoz frente a la comunidad internacional, la Comisión consolidó un rol frente a los Estados con el fin de que estos ajustaran sus normativas, políticas y prácticas a los estándares de derechos humanos. Este rol fue ejercido tanto a través del sistema de peticiones y casos, como a través del fortalecimiento de los mecanismos de monitoreo y de seguimiento de recomendaciones.

El sistema de peticiones de la CIDH ha permitido a un significativo número de víctimas y a sus familiares en nuestro continente recibir reparaciones por la violación de sus derechos. En este aspecto, son numerosos los casos que se pueden mencionar en los cuales las recomendaciones de la Comisión han derivado en que cientos de víctimas logren finalmente justicia respecto de un caso particular. Al mismo tiempo, a través de este mecanismo, la CIDH consolida una línea de trabajo transformadora de las estructuras institucionales, jurídicas y administrativas de los Estados. En otras palabras, cuando la CIDH recomienda a los Estados proveer un determinado remedio a una violación de los derechos, siempre lo hace incorporando componentes individuales y colectivos o estructurales en su decisión. De este modo, cuando los Estados han cumplido con las recomendaciones de tipo estructural introduciendo reformas institucionales y de magnitud, se logra la reparación 
y se garantiza la no repetición de las situaciones que dieron lugar a las violaciones de derechos humanos.

Hay casos que se han convertido en hitos y estándares de la región, dados sus impactos estructurales y transformadores para poblaciones y comunidades. Solo a modo de ejemplo, tenemos la aprobación e implementación de la Ley «María da Penha» contra la violencia doméstica y de género en el Brasil, con todas sus réplicas y repercusiones en el resto de América tras la emisión de recomendaciones por la Comisión en un caso concreto de violencia intrafamiliar. ${ }^{6}$

En este sentido, también podemos recordar el caso de Paloma Angélica Escobar Ledezma. ${ }^{7}$ Como consecuencia de las recomendaciones de la CIDH, se creó en México la Fiscalía Especializada en Atención a Mujeres Víctimas del Delito. Asimismo, fue en cumplimiento de recomendaciones de la Comisión en el caso de la Masacre de Riofrío ${ }^{8}$ que se crearon, en Colombia, la Escuela de Derechos Humanos y Derecho Internacional Humanitario del Ejército Nacional, y el Sistema de Recepción de Quejas por violaciones de los Derechos Humanos o del Derecho Internacional Humanitario, atribuidas a integrantes de las fuerzas militares. En Uruguay, tras la adopción de recomendaciones por la CIDH, se adoptó la ley que declara imprescriptibles los crímenes cometidos durante la dictadura; y en Chile se modificó la Constitución Política, que permitía la censura previa, en cumplimiento del caso de la película $L a$ última tentación de Cristo.

\section{El rol de las organizaciones no gubernamentales}

Es destacable, en el desarrollo de sus labores, el nivel de interacción que rápidamente adquirieron las organizaciones de la sociedad civil con la Comisión Interamericana. Estas organizaciones facilitaron y contribuyeron a fortalecer la tarea de la CIDH en la protección de los derechos humanos aportando al ejercicio de sus diversas funciones, lo cual se ha ido fortaleciendo y ampliando con el correr de las décadas.

No cabe duda de que las organizaciones de víctimas y de la sociedad civil han contribuido históricamente al cumplimiento de los mandatos de la CIDH y son un actor fundamental, en la medida en que son fuentes de información indispensables para la elaboración de los informes y las comunicaciones sobre la situación de los derechos humanos en la región. Como parte de este trabajo articulado, la CIDH celebra audiencias públicas periódicas, así como reuniones abiertas con la sociedad civil y

6. Informe 54/o1, caso 12.051, María da Penha Maia Fernandes con Brasil, Comisión Interamericana de Derechos Humanos, 16 de abril del 2001.

7. Informe 51/13, caso 12.551, Paloma Angélica Escobar Ledezma y otros con México, Comisión Interamericana de Derechos Humanos, 12 de julio del 2013.

8. Informe 62/01, caso 11.654, Masacre Riofrío con Colombia, Comisión Interamericana de Derechos Humanos, 6 de abril del 2001. 
reuniones privadas con la coalición de ONG que trabajan en el Sistema Interamericano de Derechos Humanos.

\section{Las medidas cautelares}

Uno de los principales mecanismos de protección de la CIDH son las medidas cautelares, las cuales sin duda han salvado innumerables vidas en las últimas décadas, al operar como instrumentos efectivos de protección ante posibles daños graves e irreparables a personas o grupos que enfrentan situaciones de riesgo inminente. Ésta fue, por ejemplo, la situación de Honduras en el contexto del golpe de Estado en 2009, cuando la CIDH no solo otorgó numerosas medidas cautelares para proteger la vida de las personas en riesgo, sino que tuvo un alto impacto al condenarlo a través de un comunicado de prensa, el cual fue tomado como referencia por la OEA para la suspensión de este Estado. ${ }^{9}$ El impacto de las medidas cautelares en la grave crisis de derechos humanos que atraviesa Nicaragua es otro ejemplo muy importante.

Por último, y también solo a modo de ejemplo, con ocasión de la desaparición forzada de los 43 estudiantes normalistas de Ayotzinapa, Guerrero (México), junto con el asesinato de seis personas, la Comisión adoptó la medida cautelar 409-14, ${ }^{10}$ y solicitó al Estado mexicano tomar medidas para la búsqueda de los estudiantes, la investigación de los hechos y la atención a las víctimas de los ataques. Luego, en consenso con el Estado y los representantes de los familiares, la CIDH creó un grupo interdisciplinario de expertos independientes, ${ }^{11}$ que brindó asistencia técnica a las autoridades estatales y presentó las conclusiones de su trabajo en dos informes con recomendaciones dirigidas al Estado.

\section{Otros mecanismos y estrategias para la efectividad de la CIDH: Plan Estratégico 2017-2021 y mecanismos especiales}

La consolidación del impacto de las acciones de la CIDH ha continuado también a través de múltiples instrumentos, que incluyen las actividades de las relatorías, producción de informes temáticos e informes de país, audiencias públicas, reuniones de trabajo, además de los informes anuales y la emisión constante de comunicados de prensa y, en los últimos años, pronunciamientos vía Twitter.

9. «Comunicado de prensa 42/o9: CIDH condena enérgicamente el golpe de Estado en Honduras», Comisión Interamericana de Derechos Humanos, 28 de junio de 2009.

10. «Resolución 18/2014, MC 409-14: Estudiantes de la escuela rural Raúl Isidro Burgos respecto del Estado de México», Comisión Interamericana de Derechos Humanos, 3 de octubre de 2014.

11. «Comunicado de prensa 136/14: CIDH oficializa acuerdo de cooperación técnica sobre estudiantes de Ayotzinapa, México», Comisión Interamericana de Derechos Humanos, 18 de noviembre de 2014. 
Este recorrido histórico revela la sólida configuración institucional y jurídica de la CIDH hasta hoy, la cual se estructura sobre tres pilares fundamentales: el pilar de peticiones y casos - que incluye las medidas cautelares-, el pilar de monitoreo y el pilar de promoción y cooperación técnica con los Estados. Sobre estas columnas, la $\mathrm{CIDH}$ aprobó su Plan Estratégico 2017-2021, ${ }^{12}$ elaborado con una amplia participación de la sociedad civil y de los Estados, y que identificó e introdujo nuevas formas de abordar las coyunturas y problemáticas actuales de derechos humanos en la región.

Con ese propósito, la CIDH reforzó sus estrategias para buscar la efectividad del sistema a través de un programa especial transversal de seguimiento. En este marco, estableció mecanismos especiales para dar seguimiento a la implementación de sus recomendaciones, práctica de vanguardia en el contexto del derecho internacional de los derechos humanos. En efecto, durante los últimos años, la Comisión ha empezado una práctica novedosa de establecer mecanismos especiales para dar seguimiento a la implementación de las recomendaciones realizadas ante situaciones específicas.

Los mecanismos especiales de seguimiento facilitan un análisis más holístico de las decisiones y recomendaciones de la $\mathrm{CIDH}$, dan una exposición pública al caso o la situación, y dan un sistemático seguimiento periódico al tema, lo que resulta en un seguimiento más profundo y enfocado por parte de la CIDH. ${ }^{13}$ Menciono solo como ejemplo el Mecanismo Especial de Seguimiento al Asunto Ayotzinapa (MESA), junto con el Grupo Interdisciplinario de Expertos Independientes; y el Mecanismo Especial de Seguimiento para Nicaragua (MESENI), junto con el Grupo Interdisciplinario de Expertos Independientes. ${ }^{14}$ Más recientemente, la CIDH creó un Mecanismos Especial para Venezuela (MESEVE).

Los mecanismos especiales de investigación creados en el marco de recomendaciones de la $\mathrm{CIDH}$, como instrumentos novedosos, son herramientas muy útiles en el actual escenario de la región, pues permiten dar una visión integral a una situación de derechos humanos determinada y establecer estrategias de implementación conjuntas con los diversos actores. El tema es - como todo lo relacionado con el cumplimiento de las recomendaciones y sentencias de los órganos del sistema- la voluntad de los Estados de querer contribuir para que estos mecanismos cumplan su fin.

12. Plan Estratégico 2017-2021, Comisión Interamericana de Derechos Humanos, OEA/ser.L/V/II/61 Doc. 27/17, 20 de marzo del 2017.

13. "Comunicado de prensa: CIDH presenta el balance de resultados en 2018 de los mecanismos especiales de seguimiento de recomendaciones», Comisión Interamericana de Derechos Humanos, OEA/ Ser/l/v/II. Doc.82, 5 de junio del 2018.

14. «Comunicado de prensa: CIDH instala el Mecanismo Especial de Seguimiento de Nicaragua», Comisión Interamericana de Derechos Humanos, 25 de junio del 2018. 


\section{Impactos como medidas de reparación}

Más allá de estos mecanismos e impactos que he expresado, hay un impacto que nunca se menciona. Me permitiré un relato más personal.

Cuando partí como comisionada en 2018 asumí, entre otros países, la relatoría por Nicaragua. Tuve un bautizo bastante brusco, pues, a los pocos meses de haber asumido, estaba en una visita de trabajo en medio de la crisis de Nicaragua. Me encontré con muchachos y muchachas muy jóvenes, que no eran militantes ni activistas políticos, que se encontraron envueltos en una protesta social, algunos defendiendo a los adultos mayores que fueron reprimidos por manifestarse contrarios a una reforma al sistema de pensiones; otros por temas ambientales, relacionados con una reserva natural llamada Indio Maíz. Estos jóvenes tan solo reaccionaron por la gravísima represión de parte del Estado. Ellos tenían miedo, pero también mucho coraje.

Luego conocí a las Madres de Abril, que agrupa a las mujeres familiares, en su gran mayoría madres, de los jóvenes asesinados en el inicio de las protestas. Cuando me reuní con ellas la primera vez y escuché sus testimonios, cada una llevaba la foto y contaba quién era su hijo, qué hacía el día en que lo mataron, la gran mayoría asesinados mientras hacían uso de su legítimo derecho a la protesta. Un número muy significativo de ellos murió por disparos a la cabeza, al cuello o al tórax por francotiradores.

También tengo grabadas similares voces de pena, rabia, injusticia, de las madres afrodescendientes de las favelas de Río de Janeiro, también con las fotos de sus hijos, todos asesinados en ejecuciones extrajudiciales de la policía. Una visita in loco a El Salvador me permitió viajar a una zona campesina donde se ejecutaron numerosas masacres, tanto de parte del Ejército como de parte del Frente Farabundo Martí para la Liberación Nacional. En una escuela se juntaron víctimas de ambos bandos. Muchas mujeres cuyos hijos o hijas les fueron arrebatados de sus brazos y nunca más supieron de ellos. O hijos o hijas que buscaban a sus padres, luego de ser entregados ilegalmente en adopción a familias de militares.

Por último, menciono una reunión en Sucre, Bolivia, con organizaciones de la sociedad civil. Un grupo de niñas y un niño, todos abusados sexualmente. Habló una de ellas, habría tenido como máximo 16 años. Denunció la falta de credibilidad que sus testimonios tenían desde su entorno familiar y del sistema de justicia, la revictimización. La niña se quebró. Sus compañeras a su lado se tomaron de las manos. Lloraban, pero la niña siguió hablando hasta terminar su discurso. La Comisión en pleno y todo ese salón escuchó en silencio y luego las aplaudió.

En cada uno de estos casos, y muchos más que no menciono, hay relatos desgarradores que la $\mathrm{CIDH}$ ha escuchado de parte de miles de víctimas en el continente y que dan cuenta de un rol que no está en la Convención, ni en la Carta de la OEA, ni en el reglamento o el estatuto de la CIDH. Tampoco en los análisis doctrinarios de la jurisprudencia interamericana ni de los impactos del sistema. Me refiero al rol repa- 
ratorio que tiene la CIDH por el solo hecho de ser un espacio de testimonio para las víctimas. No es posible lograr una historia completa sin la voz de las víctimas. No es posible construir un país democrático sin que las víctimas de Estado puedan tener un espacio para contar sus historias. En su propia voz. Como dice la académica brasilera Mariana Joffily (2016), autora de un artículo sobre violencia sexual en dictadura, hay que ampliar y sensibilizar nuestra escucha para los silencios que se quieren hacer oír. Pienso que muchas veces la CIDH logra ser ese espacio. A pesar de todas las dificultades que tenemos como organismo, toda la burocracia, todas las críticas, logra ser, en muchísimas ocasiones, un espacio de escucha para los silencios que se quieren hacer oír. Aquello es, a mi juicio, uno de los mayores aportes e impactos de la CIDH a las víctimas en estos 60 años de historia.

\section{Contexto regional: Avances y retrocesos}

\section{Contexto regional actual}

En las últimas décadas, la región ha sido testigo de importantes avances, en especial a partir del final de las dictaduras militares en el Cono Sur y el fin de los conflictos armados en América Central. Se han registrado grandes progresos en materia de institucionalidad y de políticas públicas con enfoque de derechos humanos. Cabe mencionar, de manera general, la creación de nuevos espacios institucionales para la promoción y protección en derechos humanos en varios países, así como la participación democrática de grupos históricamente discriminados; la adopción e implementación de planes nacionales de derechos humanos; la garantía del derecho al voto con respeto de la identidad de género; el avance en los sistemas de verdad, justicia, reparación y no repetición; la creación de nuevos mecanismos para la búsqueda de personas desaparecidas; y el establecimiento de la responsabilidad civil por violaciones a los derechos humanos, entre otros.

Sin embargo, en los últimos años hemos sido testigos de demandas sociales vinculadas a la exigencia de mayores niveles de inclusión e igualdad. La Comisión viene advirtiendo esta situación y ha señalado que la exclusión social, la falta de acceso a la justicia y la fragilidad de los servicios públicos constituyen factores limitantes de las condiciones de desarrollo. Desde esta perspectiva, no podemos desconocer que subsisten aún serias situaciones que conspiran contra el pleno goce de los derechos inherentes de nuestros pueblos. De manera no taxativa, y a la luz de los informes anuales de la CIDH de 2018 y 2019, menciono los siguientes:

Primero, la discriminación a la que se ven sometidas las personas LGBTI, personas afrodescendientes, indígenas, defensoras y defensores de derechos humanos, mujeres, niños, niñas, adolescentes, personas con discapacidad y personas mayores, aun cuando muchos de los Estados han receptado en sus sistemas normativos las de- 
claraciones y principios que adoptamos regional e internacionalmente. El tema no es por necesidad la recepción de estos derechos en la normativa interna, lo que sin duda es un gran avance, sino la inmensa brecha de implementación que vemos en muchos países entre la norma y la práctica de parte de los agentes del Estado.

Segundo, los obstáculos y, en muchos casos, la falta absoluta de acceso a la justicia, último recurso del que podrían favorecerse las personas en situación de vulnerabilidad de un sistema que continúa siendo injusto. Existe una grave desigualdad en la región en el acceso a la justicia entre las personas en situación de vulnerabilidad y aquellos grupos en situación de privilegio.

Tercero, la creciente tendencia en la región a agravar las penas, aumentando sus plazos o criminalizando conductas que no constituían delitos, lo que concluye en un incremento de las penas privativas de la libertad. Esto conlleva a un aumento inaceptable de la población carcelaria en condiciones inhumanas, sin programas de rehabilitación y el uso abusivo de la prisión preventiva. Si a esto agregamos la grave desigualdad en el acceso a la justicia y en la manera de impartirla, las conclusiones son evidentes.

Cuarto, los movimientos migratorios de poblaciones dentro y fuera de los países de la región, que arrojan cifras que nos interpelan: las migraciones forzadas de algunos de nuestros países representan un volumen no desdeñable en el mapa mundial de las migraciones. No podemos ni debemos ignorar que estas movilizaciones reconocen su causa en diversos tipos de violencias que empujan a millones de personas a dejar sus comunidades y sus familias.

Quinto, el preocupante incremento de discursos que distorsionan, desprestigian y estigmatizan el papel y la función de los derechos humanos para la sociedad. Se ha constatado una repetición de lenguaje de intolerancia y odio que afecta a las libertades de expresión, manifestación, reunión y asociación. En su sentido existencial, los derechos humanos pertenecen y se dirigen a todos, sin distinción. Su negación o su reducción al interés de una parte de la población en oposición a la totalidad de las personas tiene por objeto legitimar las violaciones.

Sexto, la persistencia de la impunidad que subsiste no solo respecto de violaciones sistemáticas ocurridas en el pasado en el contexto de las dictaduras y conflicto armado, sino también respecto de hechos del presente. Acá no solo me refiero, por ejemplo, a la desaparición forzada como delito de lesa humanidad cometido por las dictaduras del Cono Sur o durante los conflictos armados de El Salvador o Guatemala, que tienen cifras desgarradoras de personas desaparecidas, sin que se sepa hasta hoy dónde están los familiares y con intentos, en el último tiempo, por parte de algunas autoridades ejecutivas o legislativas de dictar leyes o decretos de amnistía. Me refiero también a las desapariciones que ocurren hoy, como la situación de las desapariciones de migrantes en la frontera en Estados Unidos o el fenómeno de las desapariciones en México, que alcanza, según cifras oficiales, más de 35.000 personas. 
Séptimo, los altos grados de corrupción que afectan en forma directa el ejercicio de derechos humanos, en particular de derechos económicos, sociales, culturales y ambientales, con un impacto absolutamente desproporcionado en los grupos que se encuentran en una situación de desigualdad estructural.

\section{Desafíos transversales para la CIDH en el actual contexto}

Haciendo un repaso de los últimos posicionamientos, la CIDH ha llamado a los distintos Estados de la región para la adopción de medidas de protección de derechos en temas como el uso de la fuerza, la protección de personas que ejercen su derecho a la protesta y movilización, la garantía de la seguridad, integridad personal y la libertad de expresión, la prevención de la tortura, la erradicación de la persecución por motivos políticos, la discriminación y violencia contra grupos en especial situación de vulnerabilidad, entre otros.

En ese sentido, la CIDH advierte dos importantes desafíos: por un lado, la necesidad inmediata y urgente de trabajar con los Estados, las instituciones nacionales de derechos humanos, las organizaciones de víctimas y con las organizaciones de la sociedad civil en la protección de los derechos humanos que están en juego en el marco de estas situaciones críticas que he mencionado y que protagonizan algunos de los países de la región. Por otro lado, la necesidad de reflexionar sobre el rol del Sistema Interamericano y en particular de la Comisión Interamericana en la transformación de las causas estructurales que dan lugar a la violación de los derechos humanos y que profundizan situaciones de desigualdad y discriminación a grupos en especial situación de vulnerabilidad.

Las grandes brechas de desigualdad que el continente americano presenta interpelan a repensar no solo el rol de los Estados, sino también el de los órganos internacionales de promoción y protección de derechos humanos. ¿Estamos teniendo actuaciones oportunas y adecuadas frente a las actuales crisis de derechos humanos? ¿Las herramientas que utiliza el SIDH han ido evolucionando y acompañando los desafíos de la actual coyuntura? ¿Cómo se piensa de nuevo el rol de subsidiariedad y complementariedad que tiene el Sistema Interamericano frente a las actuales respuestas que dan los Estados a nivel local?

Éstas son algunas preguntas que desde el Sistema Interamericano de Derechos Humanos y en particular desde la CIDH nos venimos haciendo, a las que vamos encontrando respuestas a través de los diálogos permanentes con las organizaciones de la sociedad civil, los Estados y otros actores relevantes de la región.

Frente a un panorama que podríamos calificar como desalentador, en esos diálogos y reflexiones que hacemos desde el propio SIDH, es importante recordar que hace sesenta años era impensable que un Estado reconociera públicamente su responsabilidad por los abusos cometidos contra su población. Hoy muchos de los Es- 
tados han dado este paso imprescindible para que las víctimas de violaciones de los derechos humanos encuentren justicia.

A través de las decisiones de la Comisión, los Estados han accedido a la reparación de las víctimas y de los familiares de víctimas de graves violaciones a los derechos humanos, como masacres, ejecuciones extrajudiciales, desapariciones forzadas, torturas y detenciones ilegales.

Los Estados de la región han incorporado en sus constituciones nacionales y en sus leyes las declaraciones y principios reconocidos en los instrumentos del Sistema Interamericano. Muchos de los mayores avances normativos tuvieron su origen en recomendaciones de la CIDH y, sin duda, la formulación y ejecución de políticas públicas con enfoque de derechos humanos también deben reconocerle su influencia. En ese sentido, procurando acompañar la evolución que está teniendo el derecho internacional de los derechos humanos, la CIDH ha incorporado, a través de su Plan Estratégico, nuevas formas de abordar las coyunturas y problemáticas actuales de derechos humanos en la región.

Así, como mencioné en el acápite anterior, la Comisión instrumentó mecanismos especiales de seguimiento de sus recomendaciones. Esto constituye una práctica novedosa en el contexto del derecho internacional de los derechos humanos, en tanto facilita un análisis integral de las decisiones y de las recomendaciones, otorgando una exposición pública al caso o a la situación bajo estudio, lo que asegura su seguimiento permanente y focalizado.

Estos mecanismos de seguimiento, creados a partir de situaciones en las que se hace evidente la grave violación de derechos humanos, constituyen instrumentos novedosos que permiten consolidar el trabajo de la Comisión.

Desde el caso de Ayotzinapa, México, se ha iniciado un mecanismo para coadyuvar en la investigación, búsqueda y atención a las víctimas. El Grupo Interdisciplinario de Expertos Independientes (GIEI) fue creado como mecanismo novedoso para cumplir una medida cautelar decretada por la CIDH en este caso que convulsionó a México. A partir de esta experiencia exitosa - aunque no exenta de dificultades-, la $\mathrm{CIDH}$ propuso un mecanismo similar para coadyuvar en las investigaciones a los hechos violentos acaecidos en Nicaragua. Si bien se trata de mecanismos similares, los contextos son muy distintos y conllevan desafíos propios.

No es del caso analizar en este trabajo estos mecanismos creados en el marco de recomendaciones de la CIDH como instrumentos novedosos, precisamente para dar respuesta oportuna a las actuales y cambiantes coyunturas. Son herramientas que, en el actual escenario de la región, con un alto grado de desconfianza en los órganos a cargo de investigar y sancionar a los responsables, pueden ayudar.

Sin embargo, es necesario recordar que el Sistema Interamericano de Derechos Humanos tiene carácter subsidiario, coadyuvante y complementario de la actuación de los Estados que integran la organización. Es obvio que la obligación de promover y 
garantizar el conocimiento y el respeto de los derechos contenidos en la Convención Americana de Derechos Humanos corresponde, en primer lugar, a los Estados. Estos mecanismos han resultado muy importantes y necesarios, pero urge reflexionar en torno a sus objetivos y en cómo ellos dialogan y se coordinan con los mecanismos propios y convencionales del Sistema.

Lo cierto es que corresponde a los Estados darse una estructura organizativa y funcional que asegure el cumplimiento de las obligaciones que asumieron de manera libre y soberana, y son ellos los que deben garantizar y facilitar el trabajo autónomo de los órganos de protección de derechos humanos y cumplir de buena fe con todas las recomendaciones y decisiones que el Sistema adopte en ejercicio de sus mandatos. A su vez, los mecanismos del Sistema no deben sustituir el rol de los Estados. Con este espíritu, el Plan Estratégico de la CIDH, ya mencionado, previó la creación del Programa de Cooperación Técnica en Materia de Institucionalidad y Políticas Públicas, con enfoque en derechos humanos.

En la actualidad, democracia y derechos humanos son conceptos que se encuentran fuertemente vinculados: no es posible concebir la democracia sin el ejercicio de los derechos humanos; de igual modo, no hay garantías absolutas de respeto, protección y cumplimiento de los derechos humanos sin libertades democráticas. Hoy en día, los derechos humanos son pensados no solo como un límite a la opresión y al autoritarismo, sino también como una guía para el desarrollo de políticas públicas y el fortalecimiento de las instituciones democráticas. Ello ha implicado un cambio en la concepción del rol de los Estados, que deben tanto respetar los derechos humanos, como promover acciones efectivas para garantizar su ejercicio.

En este sentido, un desafío prioritario para la $\mathrm{CIDH}$ es el fortalecimiento de la institucionalidad democrática de los Estados, así como de sus capacidades para implementar políticas públicas con enfoque en derechos humanos, que puedan generar impactos reales y concretos en su goce y ejercicio. De allí que la cooperación técnica con los Estados resulta prioritaria.

Sin duda, existe un conjunto de otros desafíos pendientes, como los relativos a la universalización del sistema y el reconocimiento de la competencia de la Corte Interamericana; al pleno cumplimiento de las decisiones de la Comisión y de la Corte; el financiamiento del Sistema por la vía del presupuesto regular, ${ }^{15} \mathrm{y}$ los avances respecto del atraso procesal de la $\mathrm{CIDH}$, ambos con una incidencia directa sobre la verdadera efectividad del Sistema Interamericano de Derechos Humanos y, por tanto, para un mejor goce y protección de derechos humanos de las poblaciones en las Américas.

15. Más allá del Acuerdo de Cancún, que suscribieron los Estados en la Asamblea General de la OEA en junio del 2017 para darle estabilidad financiera al Sistema Interamericano de Derechos Humanos por tres años. 


\section{Desafíos temáticos de la CIDH}

\section{Corrupción y efectos sobre los derechos humanos}

En 2018, por medio de la Resolución 1/18, la Comisión publicó un conjunto de recomendaciones a los Estados en que considera que la corrupción afecta a los derechos humanos en su integralidad (civiles, políticos, económicos, sociales, culturales y ambientales), así como al derecho al desarrollo, debilita la gobernabilidad y las instituciones democráticas, fomenta la impunidad, socava el Estado de derecho y exacerba la desigualdad. A través del fenómeno de la corrupción, los actores involucrados capturan las entidades estatales, influyen en los procesos electorales y debilitan la institucionalidad pública y el sistema democrático. Un desafío para el sistema es cómo abordar el fenómeno desde un enfoque de derechos humanos, haciendo alianzas con los Estados y el sector privado, además de las organizaciones académicas y de la sociedad civil.

La CIDH presentó un informe temático sobre el tema en diciembre del 2019, ${ }^{16} \mathrm{el}$ cual da cuenta del fenómeno de la corrupción desde la perspectiva de derechos humanos a la luz de los estándares interamericanos. Como ya señalé, el informe muestra cómo la lucha contra la corrupción, en sus modalidades en América Latina y el Caribe y con distintos alcances, daña la institucionalidad democrática, el Estado de derecho y, por consiguiente, el ejercicio y garantía de los derechos humanos. Cómo la $\mathrm{CIDH}$, a través de sus diversos mecanismos, enfrenta aquello, es un desafío para el futuro. La Resolución y el informe temático dan de cuenta que la CIDH está abordando la temática. Su desafío es adecuar sus mecanismos para dar una respuesta adecuada y eficaz a este flagelo.

\section{Rol de las empresas}

Las empresas y el sector privado se han convertido en actores claves. La CIDH ha estado abordando el tema a través de audiencias públicas, informes temáticos ${ }^{17} \mathrm{y}$, lentamente, a través del sistema de peticiones y casos.

Hasta ahora, la jurisprudencia interamericana ha enfrentado la temática por la vía de la responsabilidad indirecta del Estado. Hay numerosos casos, sobre todo en

16. «Informe sobre corrupción y derechos humanos», Comisión Interamericana de Derechos Humanos, OAS/ser.L/V/II. Doc.236, 6 de diciembre de 2019.

17. «Pueblos indígenas, comunidades afrodescendientes y recursos naturales: Protección de derechos humanos en el contexto de extracción, explotación y desarrollo», Comisión Interamericana de Derechos Humanos, OAS/ser.L/V/II. Doc.47/15, 31 de diciembre de 2015; también, «Empresas y derechos humanos: Estándares interamericanos», Comisión Interamericana de Derechos Humanos, OEA/Ser.L/V/II. CIDH/REDESCA. Inf.1/19, 1 de noviembre de 2019. 
materia de pueblos indígenas: a modo de ejemplo, el caso Sarayaku con Ecuador explícitamente hace responsable al Estado por las actuaciones de la empresa. ${ }^{18}$ Por otra parte, en el orden interno se han hecho numerosos avances, como establecer legislaciones que regulen la responsabilidad penal de las empresas o tipifiquen los delitos ambientales. Un anuncio muy importante en este sentido fue el que hizo el Gobierno de Canadá el 2017, cuando anunció la creación del Ombudsperson Canadiense para la Responsabilidad Empresarial.

Sin embargo, un desafío importante en el Sistema Interamericano, como de alguna manera lo ha estado haciendo Naciones Unidas, es generar un debate más abierto sobre cómo involucrar a las empresas, más allá de la responsabilidad indirecta de los Estados, en la prevención, mitigación y reparación de las violaciones a los derechos humanos en la región. El sector privado es clave, por ejemplo, en la lucha contra la corrupción, como también en la efectividad de los derechos humanos frente a la crisis ambiental y de cambio climático que estamos enfrentando. Este es un desafío para el que la CIDH debe trabajar con más fuerza y que requiere una alianza de la sociedad civil, empresas, Estados y organismos internacionales financieros, como el Banco Interamericano de Desarrollo.

En mi opinión, es necesario abrirse a revisar la responsabilidad directa de las empresas en las graves violaciones a los derechos humanos. Existe una creciente preocupación internacional por incluir dimensiones que, hasta las últimas décadas, habían sido escasamente tratadas y sin las cuales resulta imposible comprender en forma cabal estos procesos, como el papel de empresarios y empresas en delitos de lesa humanidad. Un hito relevante fue el trabajo del relator especial de las Naciones Unidas, John Ruggie, para crear un marco y guías sobre la materia, que llevó a la formación de un grupo de trabajo sobre responsabilidad corporativa en el Consejo de Derechos Humanos. Otro paso fundamental fue la creación por parte de la Comisión Internacional de Juristas del Foro de Expertos Jurídicos sobre Complicidad Empresarial en Crímenes Internacionales, que publicó en 2009 un informe sobre complicidad empresarial y responsabilidad legal, con el objetivo de abordar lo que consideran un tema de gravedad e impacto. Este informe recoge experiencias históricas que muestran la relevancia de analizar el papel de estos actores económicos en las violaciones a los derechos humanos, desde Núremberg hasta hoy. Sin duda, esto abre un espacio a nuevos actores en materia de derechos humanos: el rol de las empresas, tanto desde la perspectiva de agentes que pueden prevenir las violaciones a los derechos humanos a través de su deber de debida diligencia, como también agentes responsables de las violaciones a derechos humanos. Ya no solo es el Estado responsable último por los

18. Sentencia del caso Pueblos Indígenas Kichwa de Sarayaku con Ecuador, Corte Interamericana de Derechos Humanos, fondo y reparaciones, 27 de junio del 2012. 
actos de una empresa por la falta de prevención, investigación y sanción, sino también existe el rol de las empresas y sus directivos como responsables directos. ${ }^{19}$

\section{La retórica incendiaria}

Un desafío para todos los actores del Sistema Interamericano de Derechos Humanos, y muy en especial para los defensores y defensoras de derechos humanos, es cómo enfrentar la cada vez más común retórica incendiaria, no solo de personas naturales, sino de las autoridades, a través de los medios y redes sociales.

Estamos siendo testigos de una amenazante oleada de intolerancia y violencia. Los discursos de odio son un ataque a la tolerancia, la inclusión, la diversidad y la cohesión social, y una justificación a la violación a los derechos humanos. Se trata de un fenómeno cada vez más fuerte, por lo que un desafío urgente es cómo atenderlo y hacerse cargo de sus causas. Este es hoy el principal reto para quienes nos encontramos en el área de los derechos humanos, sea desde los órganos, desde la academia o desde la sociedad civil.

\section{La CIDH en tiempos de pandemia}

\section{Contexto y temas surgentes a propósito de la pandemia}

Cuando se me invitó a escribir en esta publicación, el coronavirus aún no se asomaba. Mi trabajo estaba enfocado en los desafíos de la CIDH en el actual contexto de derechos humanos, entendiendo por actual lo descrito en los párrafos anteriores. Sin embargo, para cuando quedaban pocos días para entregar el trabajo, el mundo era otro. En estos días me resulta imposible analizar los desafíos de la CIDH y sus impactos en el actual contexto mientras escribo desde mi casa en cuarentena. En efecto, la situación de salud pública mundial ocasionada por el covid-19, declarada como pandemia por la Organización Mundial de la Salud (OMS) el 11 de marzo de 2020, obligó a los distintos Gobiernos del mundo a adoptar medidas que, en muchos casos, han implicado acudir a las facultades que otorgan los ordenamientos jurídicos para actuar en situaciones de anormalidad.

En estas semanas, el mundo atraviesa una situación excepcional. En estos días escucho en las noticias que casi un tercio de la humanidad se halla en situación de confinamiento obligatorio o distanciamiento social. Se cierran fronteras externas, se instalan controles internos, se expanden las medidas de seguridad y control. Aquéllos

19. En Argentina se publicó un informe de CELS, Flacso-Argentina, el Programa Verdad y Justicia y la Secretaría de Derechos Humanos, ambos del Ministerio de Justicia y Derechos Humanos de la Nación, precisamente sobre responsabilidad empresarial en delitos de lesa humanidad (CELS, 2015). 
que hace unos meses defendían políticas de reducción del Estado, hoy rearman su discurso en torno a la necesaria intervención estatal.

La pandemia ha puesto de manifiesto el alcance de las desigualdades sociales y la enorme tendencia a la concentración de la riqueza que existe en el planeta. Si bien el virus afecta a todas las personas, no afecta a todas de la misma manera. La crisis ha revelado la inequidad social y cómo las diferentes formas de exclusión, desigualdad y violaciones de derechos humanos están interconectadas.

Como se puede concluir en la primera parte de este trabajo, la pandemia llega en un momento en que la democracia ya estaba bajo amenaza en muchos lugares del mundo; en el caso de América Latina, en un contexto de graves retrocesos en materia de derechos humanos. Es en este contexto que la lucha contra la pandemia ha pasado, en la gran mayoría de las naciones, a ser una prioridad absoluta. Más de 50 países han hecho uso de los estados de emergencia que sus marcos normativos les permiten. La grave emergencia sanitaria requiere medidas extraordinarias para enfrentarla, pero tales medidas deben cumplir con estándares mínimos de necesidad, transparencia y proporcionalidad. Es crucial, además, que actúen por un período determinado y sujetas a revisiones periódicas. La gran mayoría de las personas comprende que las medidas excepcionales se toman para preservar la vida, y que por tanto se justifican. Sin embargo, aparecen voces que alertan sobre la declaración de estados de emergencia sin debate previo, y que algunos Gobiernos han hecho un uso abusivo de la pandemia para expandir sus poderes ejecutivos y restringir los derechos individuales. De allí que organismos como la CIDH deben estar alertas a de qué forma el covid-19 afectará otros aspectos, como el de la gobernabilidad democrática, las libertades civiles, los procesos electorales, el control civil sobre los militares y -el mayor temor de muchos- la potencialidad de determinar el debate respecto de los méritos entre autoritarismo y democracia. Por otra parte, la movilización de las organizaciones de la sociedad civil puede reforzar la vitalidad de las democracias a nivel local.

La pandemia del covid-19 ha afectado a distintos sectores de la población, pero sobre todo a los grupos más vulnerables, pueblos indígenas, afrodescendientes, mujeres y a los trabajadores informales. Asimismo, se ha puesto en evidencia cómo la pandemia afecta en forma severa a las personas que viven en espacios inadecuados, en asentamientos en condiciones precarias o no reconocidos, con servicios carentes o en la calle. Como nunca antes, aparece con fuerza el derecho de las personas a la salud como un derecho autónomo y no derivado de otros, como el derecho a la vida, además de la importancia del derecho a la vivienda adecuada, ya que este puede ser un factor vital para impedir daños irreparables a la salud y la vida de las personas.

Otro gran tema que surge en medio de esta crisis es cómo se está usando la tecnología en algunos países para enfrentar la pandemia. La pregunta permanente es 
hasta qué punto están las personas dispuestas a intercambiar privacidad tecnológica y digital por más seguridad, y no solo en términos de salud. Esta pandemia implicará repensar los protocolos de privacidad relacionados con la tecnología: ¿es justificable una reducción de mi privacidad si se trata de cuidar la salud pública? ¿En qué pie queda el derecho a la privacidad y la protección de datos en este nuevo escenario?

Por otra parte, un tema particular que sobresale en estos días es el mayor control sobre la libertad de expresión y los medios de comunicación, bajo la justificación de que hay que luchar contra la desinformación. Los medios de comunicación y las redes sociales son fundamentales para visibilizar y denunciar posibles abusos. Precisamente por ello, algunos gobernantes autoritarios han restringido $-\mathrm{o}$ intentado restringir- estas libertades.

Asimismo, existe el riesgo de que, ante la necesidad de adoptar medidas de distanciamiento social, los Gobiernos las usen como pretexto para reprimir cualquier forma de protesta antigubernamental. Es esencial monitorear que las prohibiciones de manifestaciones públicas no sean definitivas ni aplicadas de manera discriminatoria solo para grupos determinados.

En medio de este contexto, un contrapeso clave para equilibrar estos poderes excepcionales han sido el Poder Judicial y Legislativo. Lo que sin duda esta pandemia ha puesto de relieve es que más que nunca el Estado de derecho y las democracias fuertes son los mecanismos más eficientes para proteger los derechos y garantías de las personas, sobre todo en el marco de situaciones extremas, como el covid-19 está demostrando ser.

\section{La reacción de la CIDH ante la pandemia covid-19}

En este contexto, es lógico que la CIDH no pueda estar ausente. Por ello, en marzo de 2020 publicó y adoptó una serie de comunicados y decisiones para adecuarse a estos tiempos de cuarentena y anormalidad nunca antes vistos en nuestra historia moderna. Junto con manifestar su preocupación por el acceso y la libre circulación de la información durante la pandemia ${ }^{20}$ y adecuar su sistema de trabajo ante el covid$19,{ }^{21}$ la Comisión instaló una Sala de Coordinación y Respuesta Oportuna e Integra-

20. «Comunicado de prensa R58/20. Covid-19: Los Gobiernos deben promover y proteger el acceso y la libre circulación de la información durante la pandemia. Expertos internacionales», Comisión Interamericana de Derechos Humanos, 19 de marzo de 2020, disponible en https://bit.ly/2QEo8Ge.

21. «Comunicado de prensa 59/20: La CIDH comunica sistema de trabajo ante pandemia del covid-19», Comisión Interamericana de Derechos Humanos, 19 de marzo de 2020, disponible en https:// bit.ly/2YIV5J5; también: "Comunicado de prensa 83/20: La CIDH decide otorgar una prórroga de la suspensión por un mes adicional de sus plazos del sistema de peticiones, casos y soluciones por la emergencia de salud causada por el covid-19", Comisión Interamericana de Derechos Humanos, 21 de abril de 2020, disponible en https://bit.ly/2YLNhWM. 
da para atender la crisis. ${ }^{22}$ Una vez instalada esta sala de coordinación, se inició un trabajo muy intenso de parte de la Secretaría Ejecutiva y la CIDH para monitorear la situación de derechos humanos, además comprender los efectos de la pandemia y las medidas adoptadas por los Estados para hacerle frente, desde la perspectiva de derechos humanos. Fue así como la Comisión adoptó la Resolución 01/20, Pandemia y Derechos Humanos en las Américas, ${ }^{23}$ ante la emergencia sanitaria global. La Resolución se elaboró bajo la convicción de que las medidas adoptadas por los Estados en la atención y contención del virus deben tener como centro el pleno respeto de los derechos humanos. Por lo tanto, constituye una aproximación integral sobre la situación de la pandemia, en la que se recogen los estándares del Sistema Interamericano de Derechos Humanos y se formula un conjunto de recomendaciones a los Estados de la región para abordar el enfrentamiento al covid-19 desde el enfoque de derechos humanos.

La Resolución es un llamado a los Estados miembros de la OEA a adoptar en forma inmediata y transversal el enfoque centrado en los derechos humanos en cualquier estrategia, política o medida estatal dirigida a enfrentar la pandemia y sus consecuencias, incluyendo los planes para la recuperación social y económica que se formulen, los cuales deben estar apegados al respeto irrestricto de los estándares interamericanos e internacionales en materia de derechos humanos, en particular los derechos económicos, sociales, culturales y ambientales, asegurando el funcionamiento de los poderes públicos del Estado. Asimismo, la Resolución señala que las medidas que resulten en restricciones de derechos o garantías deben ajustarse a los principios pro homine, de proporcionalidad y temporalidad, y deben procurar el estricto cumplimiento de objetivos de salud pública y protección integral.

Cabe precisar que en la Resolución se señala el contexto dentro del cual se da está pandemia en las Américas, precisando, como ya hemos indicado, que es la región más desigual del planeta, caracterizada por profundas brechas sociales en que la pobreza y la pobreza extrema constituyen un problema transversal a todos los Estados de la región, así como por la falta o precariedad en el acceso al agua potable y al saneamiento, la inseguridad alimentaria, las situaciones de contaminación ambiental y la falta de viviendas o de hábitat adecuado. A esto se suman altas tasas de informalidad laboral y de trabajo e ingresos precarios, que afectan a un gran número de personas en la región y que hacen aún más preocupante el impacto socioeconómico del covid-19. Todo esto dificulta o impide a millones de personas tomar medidas

22. «Comunicado de prensa 63/20: CIDH instala su Sala de Coordinación y Respuesta Oportuna e Integrada a Crisis para la Pandemia del Covid-19», Comisión Interamericana de Derechos Humanos, 28 de marzo de 2020, disponible en https://bit.ly/2YLNwRG.

23. Comisión Interamericana de Derechos Humanos, Resolución 1/20, Pandemia y Derechos Humanos, disponible en https://bit.ly/3lu6kyK. 
básicas de prevención contra la enfermedad, en particular cuando afecta a grupos en situación de vulnerabilidad.

Por lo anterior, la Resolución se hace cargo de que la pandemia genera impactos diferenciados e interseccionales sobre los derechos económicos, sociales, culturales y ambientales para ciertos colectivos y poblaciones en situación de vulnerabilidad, por lo que se torna esencial la adopción de políticas para prevenir de manera eficaz el contagio, así como de medidas de seguridad social y el acceso a sistemas de salud pública que faciliten el diagnóstico y tratamiento oportuno y asequible. Esto con el fin de brindar a las poblaciones en situación de vulnerabilidad la atención integral de la salud física y mental, sin discriminación.

Es importante resaltar que un apartado especial de las recomendaciones se refiere a los grupos en especial situación de vulnerabilidad, como las personas mayores, las personas privadas de libertad, las mujeres, los pueblos indígenas, las personas en situación de movilidad humana, los niños, niñas y adolescentes, las personas LGBTI, las personas afrodescendientes y las personas con discapacidad. En ese sentido, la Comisión destaca que, al momento de emitir medidas de emergencia y contención frente a la pandemia, los Estados de la región deben brindar y aplicar perspectivas interseccionales y prestar particular atención a las necesidades y al impacto diferenciado de dichas medidas en los derechos humanos de los grupos históricamente discriminados o en especial vulnerabilidad.

No cabe duda de que esta Resolución ha sido una reacción clara, adecuada y oportuna de la CIDH a una situación muy grave y también desafiante para todos los actores regionales. En ese sentido, fue bienvenida por distintas autoridades nacionales, tanto del Ejecutivo como autoridades judiciales, pues establece recomendaciones en materia de políticas públicas en un contexto complejo para los gobernantes. Asimismo, es preciso señalar que al cierre de este artículo, la Resolución estaba ya produciendo un verdadero impacto en las decisiones internas de diversos países, además de recoger las principales preocupaciones de las organizaciones de la sociedad civil. Menciono solo algunos ejemplos:

El Supremo Tribunal Federal de Brasil invalidó un decreto del presidente Jair Bolsonaro que restringía el acceso a la información pública en esta coyuntura, y emitió una medida cautelar ordenando a la Presidencia de la República que aclare las medidas que el Gobierno federal viene adoptando para cumplir las medidas de prevención y mitigación recomendadas por la OMS. En la decisión se menciona la Resolución de la CIDH como antecedente. ${ }^{24}$

La Sala Constitucional de la Corte Suprema de El Salvador emitió la Resolución 148-2020, que otorgó medidas cautelares a favor de personas que habían sido deteni-

24. Véase Resolución «Medida Cautelar na Ação Direta de Inconstitucionalidade 6.363 Distrito Federal», disponible en https://bit.ly/34SUuIN. 
das para que cumplan cuarentena obligatoria en centros de contención, disponiendo entre otras cosas que puedan cumplirla en sus domicilios respetando determinados protocolos sanitarios. También esta decisión judicial menciona expresamente la Resolución $1 / 20$ de la CIDH. ${ }^{25}$

Por su parte, la Resolución 70/2020 de la Agencia de Acceso a la Información Pública de Argentina, que regula el acceso a la información en el contexto de la pandemia, hace referencia explícita a la resolución de la CIDH en comento. ${ }^{26}$

Por otra parte, en el debate respecto de medidas para evitar mayores hacinamientos en las cárceles, el presidente de Argentina también ha reiterado en varias oportunidades - en discursos, entrevistas y Twitter- las recomendaciones de la CIDH sobre las personas privadas de libertad en el contexto de la emergencia sanitaria. ${ }^{27}$

En este mismo tema, el ministro de Justicia de Chile, al defender el proyecto de ley de indulto conmutativo para personas privadas de libertad, también aludió a las recomendaciones de la CIDH en la materia. ${ }^{28}$

Además de la Resolución, la CIDH ha ido elaborando comunicados específicos en las últimas semanas respecto de distintos grupos vulnerables o temas, como las consecuencias de la pandemia en niñas, niños y adolescentes; los derechos de las personas mayores frente a la pandemia; recomendaciones a los Estados para garantizar los derechos de las personas LGBTI en este contexto; la protección de las personas migrantes, refugiadas y desplazadas frente al covid-19; la obligación de los Estados de que los estados de excepción que declaren cumplan con los estándares internacionales; la necesidad de que los Estados incorporen la perspectiva de género en la respuesta a la pandemia y a combatir la violencia sexual e intrafamiliar en este contexto; la protección de los pueblos indígenas; y la obligación de garantizar la salud e integridad de las personas privadas de libertad y de sus familiares en este contexto, entre otras.

\section{Reflexiones finales}

El Sistema Interamericano tiene carácter subsidiario, coadyuvante y complementario, por lo que la obligación de respeto y garantía de todos los derechos contenidos en la Convención Americana corresponde en primer lugar al Estado. Esto implica que

25. Resolución 148-2020 Ac. habeas corpus, Sala de lo Constitucional de la Corte Suprema de Justicia, San Salvador, 15 de abril de 2020.

26. Agencia de Acceso a la Información Pública de Argentina, Resolución 70/2020, disponible en https://bit.ly/2YKсуз K.

27. Consúltese en este sentido la cuenta de Twitter de Alberto Fernández, disponible en https://bit. ly/32LgxOW.

28. Carlos Reyes, «Ministro Larraín valora recomendaciones realizadas por la CIDH por avance del coronavirus», La Tercera, 30 de abril de 2020, disponible en https://bit.ly/3jrahlZ. 
debe organizar todo su aparato en el ámbito interno para cumplir tales obligaciones asumidas de manera libre y soberana. De igual modo, el Estado tiene la obligación de garantizar y facilitar el trabajo autónomo de los órganos de protección de derechos humanos, y de cumplir de buena fe todas las recomendaciones y decisiones que estos adopten en ejercicio de su mandato.

La experiencia de seis décadas de la Comisión Interamericana demuestra que el avance de los derechos humanos se logra mediante una combinación de esfuerzos por parte de la sociedad civil, los Estados y las propias víctimas.

Lo cierto es que democracia y derechos humanos son conceptos que se encuentran vinculados de manera indisoluble, como lo reconoce la Carta Democrática Interamericana. No puede concebirse la democracia sin el ejercicio de los derechos humanos ni la garantía de respeto, protección y cumplimiento de estos sin libertades democráticas. Los derechos humanos no son solo un límite a la opresión y al autoritarismo, sino también una guía para el desarrollo de políticas públicas y el fortalecimiento de las instituciones democráticas. Ello ha implicado un cambio en la concepción del rol de los Estados, que deben respetar los derechos humanos y promover acciones efectivas para garantizar su ejercicio.

El nuevo contexto de la pandemia se ha convertido en estos tiempos en un debate central. En él, la lucha por los derechos humanos definirá la calidad de vida y del bienestar de los pueblos alrededor del mundo. En estos días sabemos que el covid-19 cambiará el mundo, pero no tenemos certezas de hacia dónde. En este paraíso de incertidumbres, han aparecido muchísimos análisis de intelectuales como Slavoj Žižek, Byung-Chul Han o Giorgio Agamben. Ellos han hecho predicciones que varían entre la estocada final al capitalismo, teorías conspirativas y futuros sombríos de más aislamiento e individualismo.

Para algunos, el capitalismo ha llegado a su fin. No puede continuar desarrollándose moral y éticamente. Para otros, tras la pandemia, el capitalismo continuará con aún más pujanza, y es posible que incluso llegue a Occidente el Estado policial digital al estilo chino. Para otros, el virus ha generado un nuevo sentimiento colectivo de solidaridad que nos permite soñar con una sociedad distinta, más pacífica, más justa. Lo cierto es que, sea cual sea este futuro pospandemia que nos espera, la $\mathrm{CIDH}$ en particular y los sistemas regionales de protección en general deberán enfrentarlos con mecanismos novedosos y que respondan en tiempos adecuados a las nuevas modalidades de amenazas a los derechos humanos.

\section{Reconocimiento}

En recuerdo de quien fuera maestro e inspiración de tantas personas defensoras de derechos humanos, José Zalaquett Daher. 


\section{Referencias}

CELS, Centro de Estudios Legales y Sociales (2015). Responsabilidad empresarial en delitos de lesa humanidad: Represión a trabajadores durante el terrorismo de Estado. Buenos Aires: Ministerio de Justicia y Derechos Humanos de la Nación. Disponible en https://bit.ly/2YLQQME.

Joffily, Mariana (2016). "Violencia sexual en las dictaduras de América Latina: ¿Quién quiere saber?». Sur 24, 13 (24):165-176. Disponible en https://bit.ly/2EIFSkr.

\section{Sobre la autora}

Antonia Urrejola Noguera es abogada de la Universidad de Chile. Postítulo en Derechos Humanos y Justicia Transicional y Comisionada de la Comisión Interamericana de Derechos Humanos, 2018-2021. Fue asesora en derechos humanos del Ministerio Secretaría General de la Presidencia de Chile. Ha sido asesora principal del secretario general de la OEA entre 2006 y 2011, y consultora de organismos internacionales como el PNUD, la OIT, Flacso, CEJA y BID en temas relacionados al Convenio 169 de la OIT y el Sistema Interamericano de Derechos Humanos. Con el retorno a la democracia en Chile, trabajó en la Comisión Especial de Pueblos Indígenas, Ministerio de Bienes Nacionales y el Ministerio de Planificación y Cooperación, especializándose en derechos de los pueblos indígenas. Fue asesora del Ministerio del Interior en temas de memoria, verdad y justicia y derechos humanos. Ha sido profesora invitada en materias del sistema interamericano de derechos humanos en diversas instituciones y universidades. Su correo electrónico es aurrejola@oas.org. 
El Anuario de Derechos Humanos es una publicación semestral de referencia y consulta en materia de derechos humanos y campos afines. Busca ser un espacio de discusión de los temas centrales en el ámbito nacional e internacional sobre derechos humanos. Es publicado desde 2005 por el Centro de Derechos Humanos de la Facultad de Derecho de la Universidad de Chile.

\author{
EDITORA GENERAL \\ Claudia Iriarte Rivas \\ ciriarter@derecho.uchile.cl \\ EDITORA DE ESTE NÚMERO \\ Liliana Galdámez Zelada \\ lgaldamez@derecho.uchile.cl \\ SITIO WEB \\ anuariocdh.uchile.cl \\ CORREO ELECTRÓNICO \\ anuario-cdh@derecho.uchile.cl \\ LICENCIA DE ESTE ARTÍCULO
}

Creative Commons Atribución Compartir Igual 4.o Internacional

\author{
कै \\ La edición de textos, el diseño editorial \\ y la conversión a formatos electrónicos de este artículo \\ estuvieron a cargo de Tipográfica \\ (www.tipografica.io)
}

